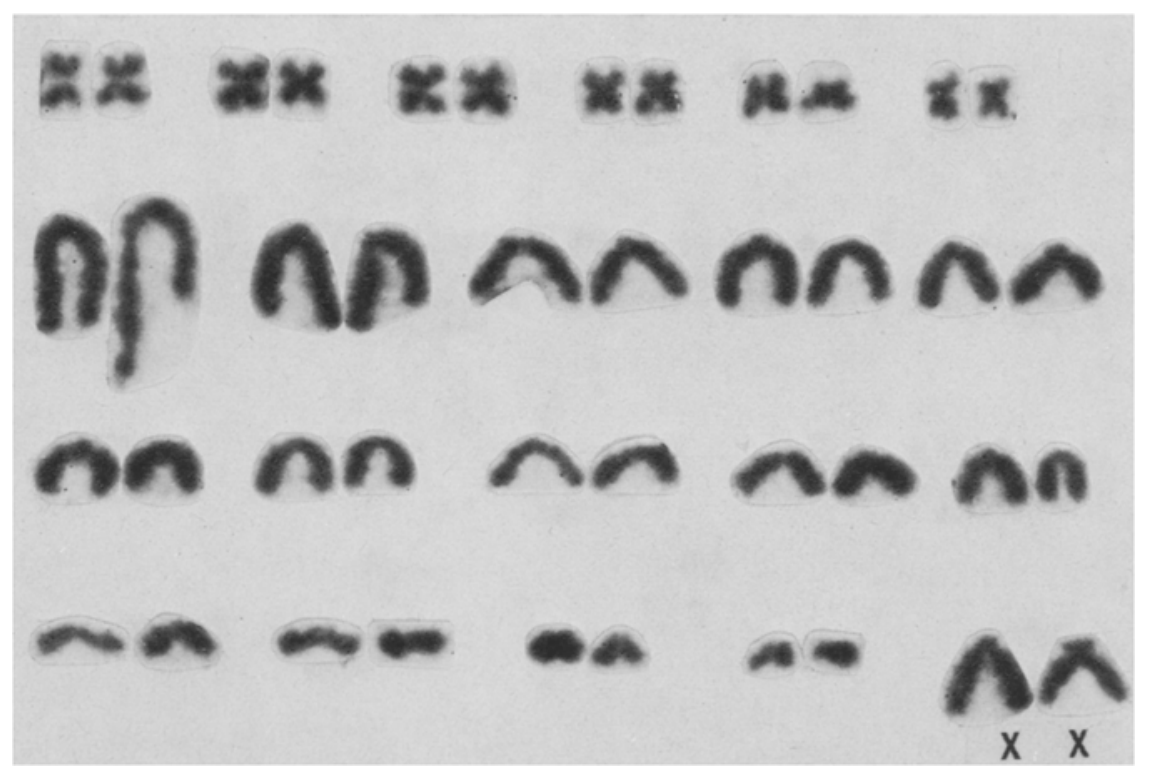

Fig. 4. Karyotype of a female $B . b$. bengalensis collected from Rohru, Himachal Pradesh. $\times 2000$.

sample and it is large-sized acrocentric chromosome in the other two samples. This variation in the morphology of the $X$ chromosome could have been brought about by a pericentric inversion. Specimens with acrocentric $X$ chromosome are separated by more than 800 miles from those with submetracentric $X$ chromosome. Since the detailed karyotypic data of the other two species of Bandicota ${ }^{3,4}$, studied by modern technique, are not available it is not possible to compare the karyotype of $B . b$. bengalensis reported in this paper.

At present, it is very difficult to speculate the direction of change in the morphology of the $X$ chromosomes in these populations. The $X$ chromosome equation, $\mathrm{SM} \leftrightarrows$ A could be reversible. Examination of additional specimens may reveal further course of $X$ chromosome variation, if any, in this subspecies ${ }^{10}$.

Résumé. Des préparations de moëlle osseuse ont permis d'établir le mombre diploïde $(2 N=42)$ et le nombre fondamental $(\mathrm{NF}=52)$ de Bandicota $b$. bengalensis (Gray), les spécimens étudiés appartement à trois popu- lations distinctes (Rohru, Varanasi, Belonia, Indes). Le nombre et la forme des autosomes sont les mêmes dans les trois échantillons alors que l' $X$ peut être acrocentrique ou submétacentrique; L' $Y$ est petit et submétacentrique.

S. PATHAK 11

Cytogenetics Laboratory, Department of Zoology,

Banaras Hindu University,

Varanasi-5 (India), 29 July 1971.

10 Supported by the University Grants Commission, India, and a grant from the Ford Foundation, USA, to Prof. Dr. S. P. RAYChaudhurt. The author is thankful to Dr. V. S. Agrawal of the Zoological Survey of India, Calcutta, and Mr. S. M. KulKarni of the Virus Research Centre, Poona, for providing and identifying the specimens. The editorial assistance of L. C. ELLETT is also appreciated.

11 Present address: Cytogenetics Laboratory, Texas Children's Hospital, Baylor College of Medicine, Texas Medical Center, Houston (Texas 77025, USA).

\title{
Second Discovery of Multiple Sex Chromosomes Among Fishes
}

The viviparous fishes of the family Goodeidae (suborder Cyprinodontoidea) are confined to Mexico. Their chromosome number and some facets of their biology and classification were recently summarized by MILLER and FitzSIMONS ${ }^{1}$, who included the first karyotype for the family. They noted that the chromosome number varies from 24 to 48 in 35 (of perhaps 38 ) species. None of these species showed any detectable differences between the sexes in chromosome number or form. However, one undescribed genus, subsequently karyotyped, appears to be unique for this familiy in having a diploid number of 42 in the female and 41 in the male. Like the genus of a related group (the Cyprinodontidae) with $2 n=48$ in the female and $2 n=47$ in the male 2 , this species is known only from a single drainage basin in Mexico.
In order to obtain the chromosome figures gill epithelium was used, following the method of McPHAIL and JoNes ${ }^{3}$ with some modifications ${ }^{4}$. 60 cells of 4 females and 60 cells of 5 males were observed. Several pieces of testis tissue were squashed to obtain meiotic figures.

The female karyotype has a diploid number of 42 including 6 large metacentrics, 2 small metacentrics, 2 small

1 R. R. Miller and J. M. Fitzsimons, Copeia 1, 1 (1971).

2 T. Uyeno and R. R. MilLeR, Nature, Lond. 231, 452 (1971).

3 J. D. McPhail and R. L. Jones, J. Fish. Res. Board, Canada 23 , 767 (1966).

4 R. Beamish, Ph. D. thesis, Dept. Zool., Univ. of Toronto 1970. 


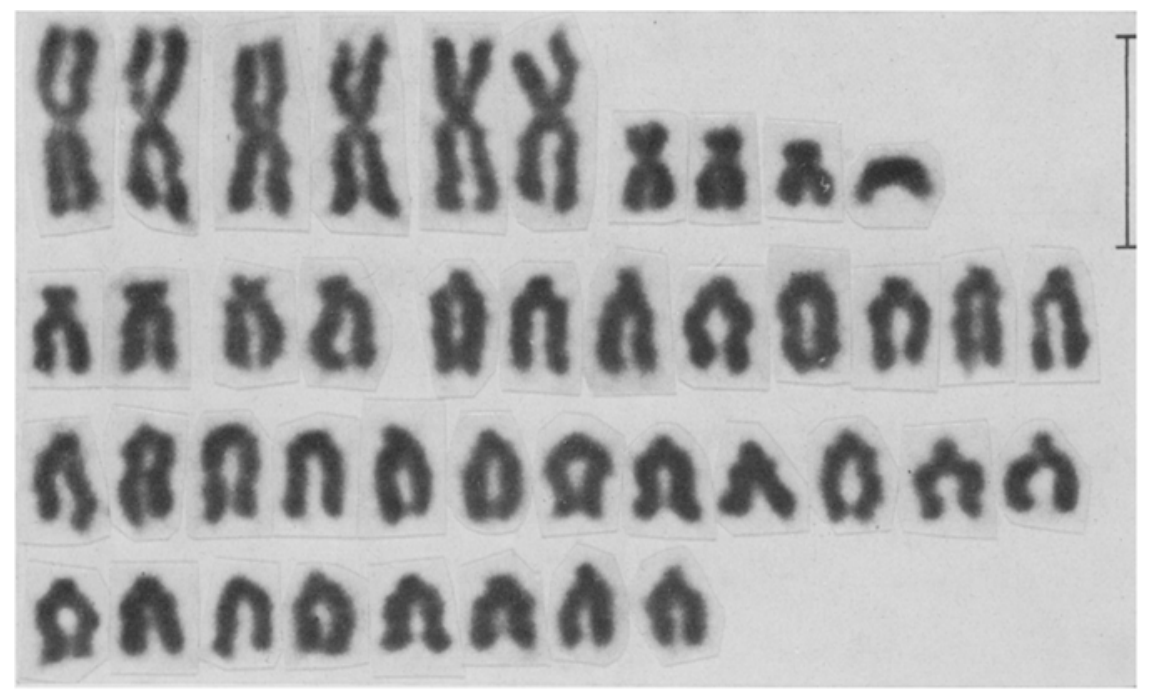

Figs. 1 and 2. Karyotype of the unnamed Mexican goodeid fish : female above, male below. Scale (in all figures) is 5 $\mu \mathrm{m}$.

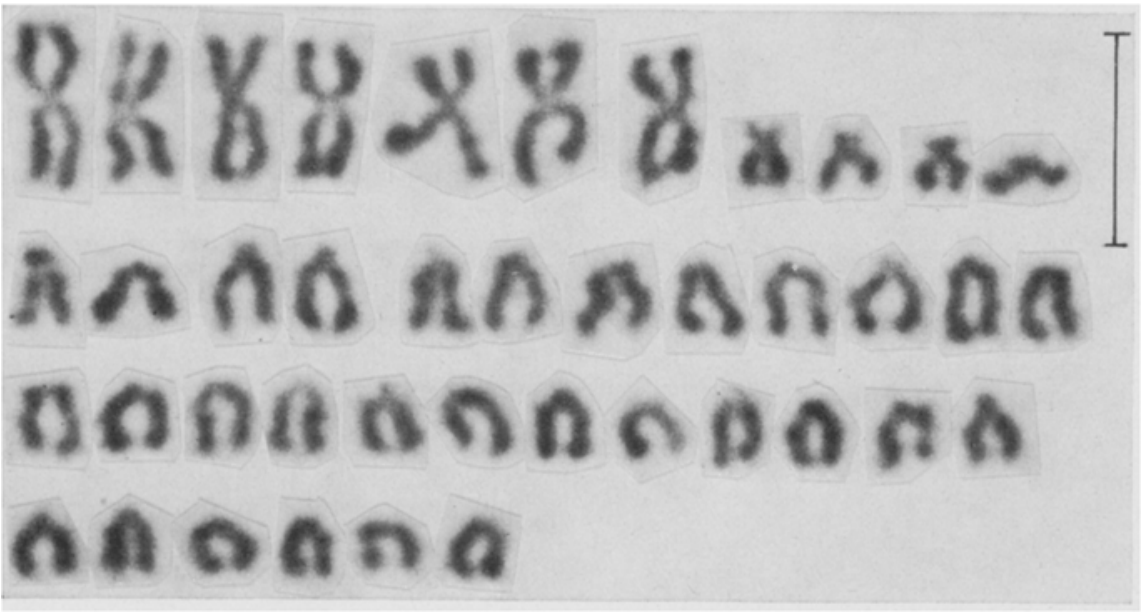

submetacentrics or subtelocentrics, 2 medium-sized subtelocentrics, and 30 acrocentrics of medium to small size. In contrast, the male karyotype invariably possesses 41 chromosomes including 7 large metacentrics, 2 small metacentrics, 2 small submetacentrics or subtelocentrics, 2 medium-sized subtelocentrics, and 28 acrocentrics of medium to small size. Thus the male has 1 more large metacentric chromosome and 2 fewer acrocentric chromosomes than the female (Figures 1-2). We therefore consider 1 of the large metacentrics in the male karyotype to be a $Y$ chromosome and believe that 2 of the acrocentrics are probably $X_{1}$ and $X_{2}$ chromosomes; in the female karyotype, we consider that 4 acrocentrics of similar size represent $X_{1} X_{1} X_{2} X_{2}$ chromosomes, because the 2 arms of the $Y$ chromosome of the male, which represent the original $Y$ and counterpart of $X_{2}$, are of equal length. The origin of the multiple sex chromosomes in this species is probably similar to the case we reported earlier ${ }^{2}$ and to the process suggested by MATthe $\mathbf{Y}^{\mathbf{5}}$ in a rodent, Mus minutoides Smith. In the testis squash, at the diakinesis in meiosis, there are 18 bivalents, 3 quadrivalents which represent large metacentrics of the somatic metaphase, and a trivalent in which $X_{1}$ and $X_{2}$ chromosomes seem attached to the $Y$ chromosome in an end-to-end association (Figure 3).

If the multiple sex chromosomes originated by centric fusion of an acrocentric autosome with the acrocentric sex chromosome, which was otherwise indistinguishable, we suspect that other species of the family Goodeidae also

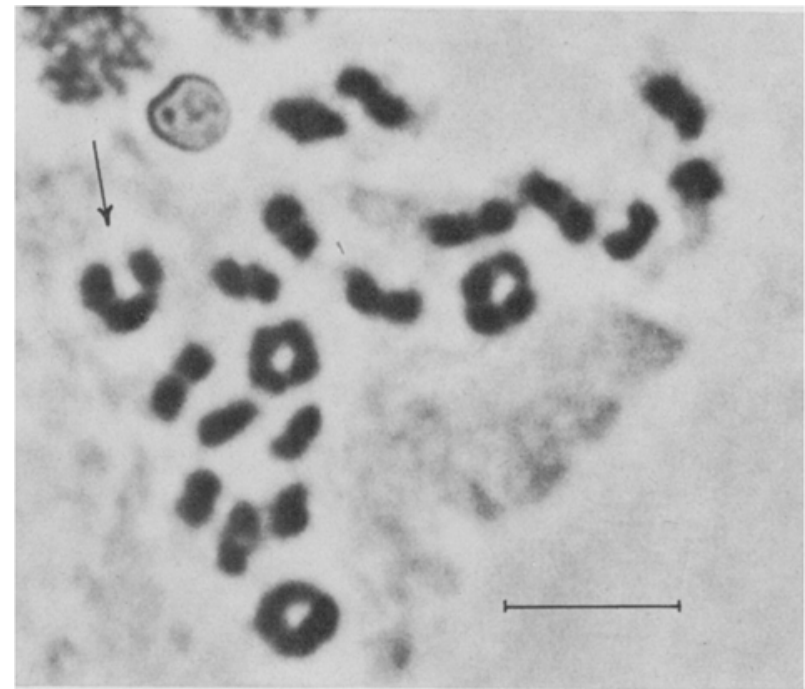

Fig. 3. Diakinesis in meiosis of the unnamed goodeid, prepared by testis squash; the arrow indicates the sex trivalent.

5 R. Matthey, Chromosoma 16, 35 (1965). 

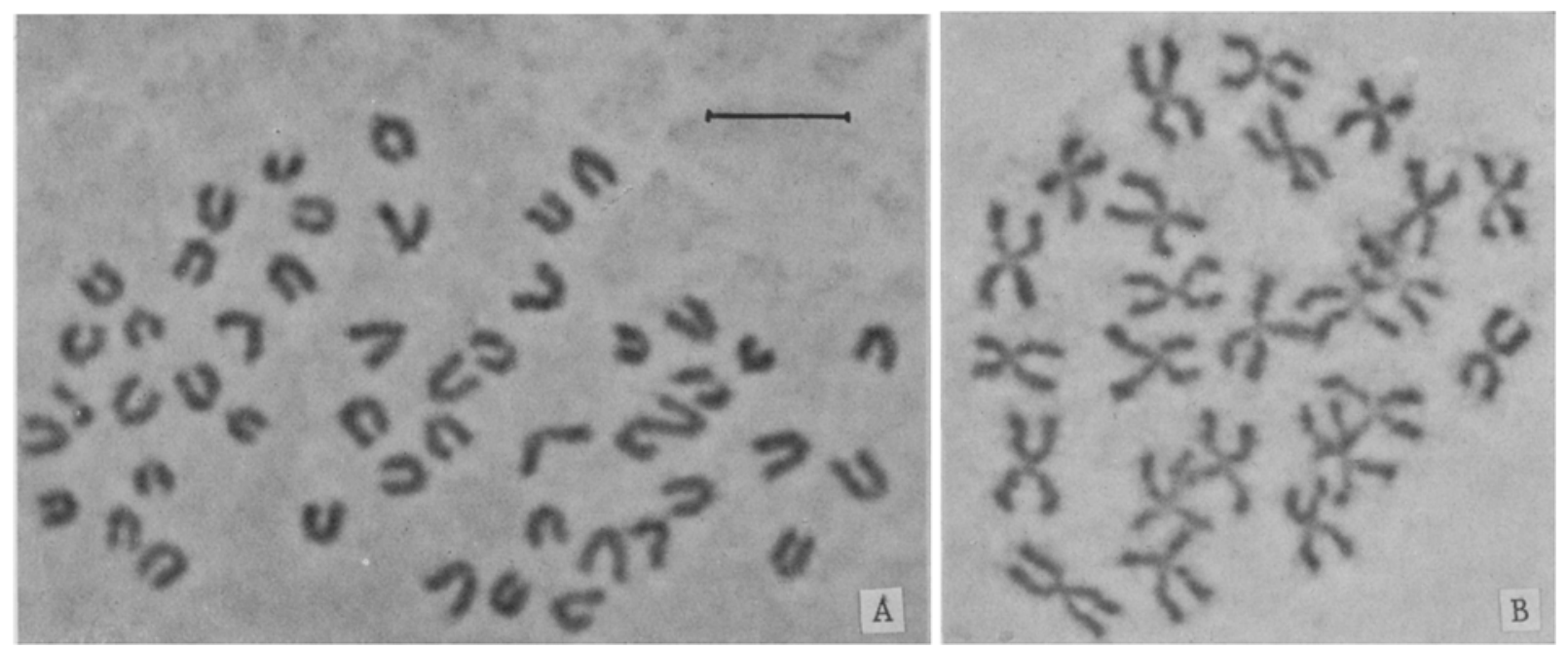

Fig. 4. Somatic chromosomes at metaphase of 2 goodeid fishes: A) Hubbsina turneri 2 n=48, and B) Characodon lateralis 2 n-24.

have $X Y$ chromosomes though they are similar and undetectable by present techniques.

Among the karyotypes of goodeid fishes, Hubbsina turneri de Buen has the simplest pattern, with 48 acrocentric chromosomes in both sexes (Figure 4a). The species with the most derived karyotype is Characodon lateralis Günther, which has 24 large metacentrics (Figure 4b) plausibly formed by Robertsonian fusions. Other goodeid species have karyotypes comprising various patterns and diploid numbers that are often reduced by centric fusions.

The ancestral karyotype of the species reported here probably had 48 chromosomes, as in the majority of species in the Goodeidae (26 among 38 examined). The diploid number was subsequently reduced by successive Robertsonian fusions, as in some other goodeids. But the involvement of the $Y$ chromosome in the fusion with an autosome produced the multiple sex chromosome system so far unique in this family, and only the second known example among fishes.

The 2 species, 1 in the family Cyprinodontidae and 1 in the Goodeidae, which were found to possess multiple sex chromosomes have several features in common: 1 . both species have a very limited distribution and are localized as small populations; 2 . both are small and exhibit distinct sexual dimorphism; 3 . both species belong to the suborder Cyprinodontoidea; 4 . both families representing these 2 fishes have species in which the karyotypes include large metacentrics derived by Robertsonian fusions; 5 . both live in Mexico; and 6. both species possess unique morphological characters among the species in their respective families (to be described elsewhere).

The specimens used in this study are preserved in the collections of the Museum of Zoology, University of Michigan $^{6}$.

Zusammenfassung. Bei einer bisher nicht beschriebenen mexikanischen Fischart werden 41 Autosomen beim Männchen und 42 beim Weibchen gefunden. Die Befunde sprechen für ein System multipler Sexualchromosomen dieser Fische.

\section{T. Uyeno ${ }^{7}$ and R. R. Miller}

Museum of Zoology, The University of Michigan, Ann Arbor (Michigan 48104, USA), 16 August 1971.

6 This research was supported by the U.S. National Science Foundation grant No. GB 14871 to R. R. Miller, and No. GB 8212 to the Museum of Zoology (N. G. Harrston), The University of Michigan. 7 Present address: Nippon Luther Shingaku Daigaku, 3-10-20 Osawa, Mitaka, Tokyo (Japan).

\section{New Evidence of a 38-Chromosomes Karyotype in South American Populations of the Roof Rat, Rattus Rattus L. (Rodentia, Muridae)}

In previous issues of this periodical, the occurrence of new cases of chromosome multiformity ${ }^{1}$ in the species Rattus vattus has been described ${ }^{2,3}$. The known 'normal' karyotype of this wide-spread and highly polytypic Eurasiatic species was reported by several authors ${ }^{4-6}$ to be composed of 42 chromosomes, among which no pair of large metacentrics is present. This karyotype was studied from strains probably derived from Japanese and European populations. More recently, it was confirmed in wild Rattus rattus from Japan, Formosa, Thailand, Philipines, Java and Celebes?, as well as from India ${ }^{8}$.

Disagreements with these results were reported earlier for strains from North America ${ }^{9,10}$ of the same species, which showed 40 chromosomes, and later by the occurrence of monomorphic populations with 38 chromosomes comprizing 2 large metacentrics in populations from Argentina and Brasil ${ }^{2,11}$ and in island and inland populations from Tuscany, Italy ${ }^{3}$. Similar monomorphic $2 n=38$ forms 